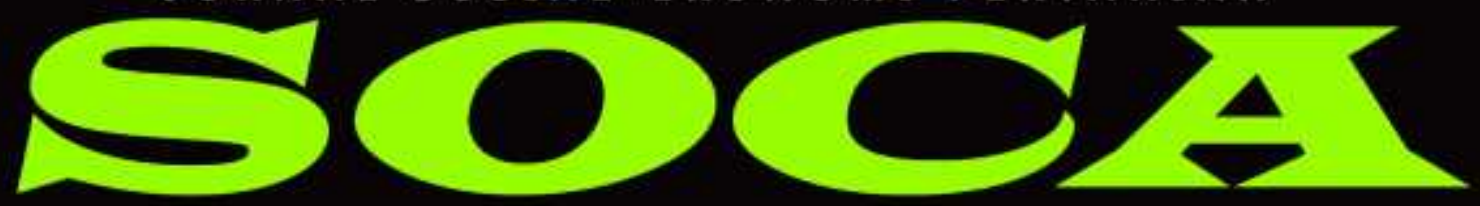

JOURNAL ON SOCIAL ECONOMICS OF AGRICULTURE

Vol.13 No.2 31 Agustus 2019

e-ISSN: $2615-6628$

p-ISSN: $1411-7176$

\title{
PERILAKU PETANI PADI ORGANIK TERHADAP RISIKO DI KECAMATAN SUSUKAN KABUPATEN SEMARANG
}

\author{
Ermelinda Bola dan Tinjung Mary Prihtanti \\ Program Studi Agribisnis, Fakultas Pertanian dan Bisnis, Universitas Kristen Satya \\ Wacana, Salatiga, Jawa Tengah \\ Email: 522014008@student.uksw.edu, \\ Telepon/HP: 081254833649
}

\begin{abstract}
ABSTRAK
Desa ketapang terletak di Kecamatan Susukan Kabupaten Semarang. Petani di desa ini sebagian besar tergabung dalam Paguyuban Petani Al- Barokah yang menerapkan sistem pertanian padi organik. Usahatani padi organik di desa Ketapang, Kabupaten Semarang telah memberikan kesadaran akan pentingnya pertanian organik. Situasi ketadakpastian selalu terjadi dalam bidang pertanian, sehingga berakibat pada hasil yang tidak pasti pula. Fluktuasi hasil pertanian (produksi) dan fluktuasi harga yang menjadi sumber ketidakpastian di sektor pertanian. (Ningsih, 2013). Penelitian ini bertujuan untuk menganalisis perilaku petani terhadap risiko usahatani padi organik dan mengetahui faktor-faktor yang mempengaruhi perilaku petani terhadap risiko di Kecamatan Susukan Kabupaten Semarang. Jumlah responden yang digunakan dalam penelitian ini 76 petani padi organik. Penelitian ini menggunakan metode survei. Pemilihan lokasi penelitian secara purposive sampling dan pengambilan sampel dilakukan melalui simple random sampling. Metode analisis perilaku petani terhadap risiko menggunakan pendekatan fungsi produksi cobb Doughlas kemudian dianalisis dengan regresi linear berganda dan untuk mengukur perilaku petani terhadap risiko menggunakan metode Moscardy dan de Janvry. Analisis linear berganda digunakan untuk mengatahui faktor -faktor yang mempengaruhi perilaku petani terhadap risiko. Penelitian ini penting dilakukan agar petani melakukan pertimbangan dalam pengelolaan dan perencanan usahatani padi organik dimasa datang serta bagi instansi sebagai masukan dalam rangka kebijakan peningkatan produksi padi organik dan mengurangi risiko usahatani padi organik. Hasil penelitian menunjukan bahwa petani padi organik di Desa Ketapang Kecamatan susukan mayoritas 76 petani (100\%) menghindari risiko atau menolak risiko (risk averter. Luas lahan dan pendapatan petani signifikan mempengaruhi perilaku petani terhadap risiko.
\end{abstract}

Kata Kunci: Perilaku, Petani, Risiko

THE RISK IN SUSUKAN SUB-DISTRICT, SEMARANG REGENCY THE BEHAVIOR OF ORGANIC RICE FARMERS TOWARDS 


\begin{abstract}
Ketapang village is located in the sub-district of Semarang district, most of the farmers in this village are members of the Al-Barokah Farmers Association which implements an organic rice farming system. Organic rice farming in the village of Ketapang, Semarang district has given awareness of the importance of organic farming. The uncertainty situation always occurs in agriculture, resulting in uncertain results. Fluctuations in agricultural products (production) and price fluctuations are sources of uncertainty in the agricultural sector. The study aims to analyze the behavior of farmers toward the risk of organic rice farming and to investigate and its determinant factors the behavior of farmers toward the risk of organic rice farming in Susukan District, Semarang Regency. The number of respondents used in this research were 76 organic rice farmers. This research uses a survey method. The research location was chosen by purposive sampling. Sampling is done through simple random sampling. The risk behavior analysis method uses the Cobb Douglas production function approach then analyzed by multiple linear regression and to measure farmers' behavior towards risk using the Moscardi and de Janvry methods. Multiple linear analysis is used to find out factors that influence farmer's behavior to risk. This research is important so that farmers take into consideration the management and planning of organic rice farming in the future as well as for agencies as input in the context of policies to increase organic rice production and reduce the risk of organic rice farming. The results showed that the majority of organic rice farmers in Ketapang Village, sub-district, 76 farmers (100\%) avoided risk or refused risk (risk averter. Land area and farmer's income significantly affected farmer's behavior to risk.
\end{abstract}

Keyword: Behavior, Farmers, Risk

\section{PENDAHULUAN}

Perkembangan pertanian di Indonesia saat ini semakin baik, dengan zaman yang semakin modern dan inovasi teknologi yang muncul dapat membantu masyarakat serta memberikan kemudahan. Teknologi yang dapat diterapkan yaitu salah satunya teknologi pertanian organik. Meskipun sistem pertanian organik dipandang memiliki sisi positif (keuntungan), namun kenyataanya di Indonesia sendiri masih sedikit masyarakat tani yang kembali menerapkan pertanian organik ini. Teknologi tersebut dapat membantu masyarakat untuk meningkatkan hasil produksi pertanian khususnya pertanian organik dan tentunya dengan penerapan teknologi yang tepat dan sesuai prosedur. Kegiatan bercocok tanam dekat dengan lingkungan serta mengurangi dan meminimalkan dampak negatif bagi alam sekitar juga merupakan sistem dari pertanian organik. Penggunaan varietas lokal yang relatif masih alami dan penggunaan pupuk dan pestisida organik serta dibudidayakan tidak menggunakan pupuk dan pestisida kimia sehingga produk terbebas dari residu zat berbahaya merupakan ciri utama dari pertanian organik. (Andoko, 2010).

Desa ketapang terletak di Kecamatan Susukan Kabupaten Semarang. Petani di desa ini sebagian besar tergabung dalam Paguyuban Petani Al- Barokah yang menerapkan sistem pertanian padi organik. Usahatani padi organik di desa Ketapang, kabupaten Semarang telah 
memberikan dampak yang baik dan memberikan kesadaran akan pentingnya pertanian organik. Batas wilayah desa ketapang yaitu sebelah utara antara Desa Sidoharjo, sebelah selatan Desa Tawang dan Desa Timpik, dan sebelah barat Desa Susukan untuk sebelah timur yaitu Desa Gentan dan Desa Bakalrejo. Luas wilayah Desa Ketapang sebanyak 316,00 hektar yang terdiri dari tanah sawah 210,00 Ha meliputi tanah sawah irigasi teknis seluas $160,00 \mathrm{Ha}$ dan sawah irigasi $1 / 2$ teknis seluas 50,00 Ha.

Situasi ketadakpastian selalu terjadi dalam bidang pertanian, sehingga berakibat pada hasil yang tidak pasti pula. Fluktuasi hasil pertanian (produksi) dan fluktuasi harga yang menjadi sumber ketidakpastian di sektor pertanian. (Ningsih, 2013). Dapat dilihat pada tabel dibawah ini produksi Petani Paguyuban Al-Barokah adalah:

Tabel 1. Produksi padi organik di desa Ketapang tahun 2018

\begin{tabular}{clcc}
\hline NO & Kelompok tani & Luas areal panen & Produksi (ton) \\
\hline 1 & Al-Barokah 1 & 6,49 & 93,88813 \\
2 & Al-Barokah 3 & 14,54 & 212,6942 \\
3 & Sunan Ampel & 6,789 & 100,9462 \\
4 & Dewi Sri & 14,483 & 512,0962 \\
5 & Ngudi Lestari & 15,85 & 230,4621 \\
6 & Mandiri & 18,26 & 203,8014 \\
7 & Walisongo & 14,33 & 205,1273 \\
8 & Al-Mazroah & 12,69 & 194,8383 \\
9 & Ngupoyo Upo & 8,9 & 134,715 \\
10 & Margo Makmur & 15,73 & 192,037 \\
11 & Langgeng Tan & 12,35 & 188,115 \\
12 & Maju Lanc & 15,98 & 144,8626 \\
13 & Tukun Karya Tani & 11,925 & 298,58 \\
\hline Jumlah Luas lahan & 168,317 & 2712,1566
\end{tabular}

Sumber : Data Primer, 2018.

Berdasarkan tabel diatas bahwa Kelompok tani di paguyuban Al-Barokah berjumlah 14 kelompok tani, dengan masing-masing jumlah areal panen yang berbeda-beda. Tiga kelompok tani dengan jumlah areal terkecil adalah kelompok tani AlBarokah 1, kelompok tani Sunan Ampel, kelompok tani Ngupoyo upo. Produksi terbesar adalah kelompok tani Dewi Sri dengan jumlah produksi sebesar 512,0962 ton dengan luas lahan 14,483 Ha, sedangkan kelompok tani Mandiri dengan luas lahan terbesar yaitu $18,26 \mathrm{Ha}$, hanya dapat menghasilkan produksi sebesar 203,8014 ton. Kondisi ini diakibatkan oleh serangan hama tikus yang lebih besar menyerang di kelompok tani Mandiri.

Peran usahatani padi dalam memenuhi kebutuhan pangan Indonesia tampaknya harus disertai dengan sifat pertanian yang rawan akan risiko, sehingga seringkali menjadi ancaman terhadap kesejahteraan petani dan khususnya petani padi organik di kecamatan 
susukan. Kondisi Alam yang tidak bersahabat dan perubahan iklim akan meningkatkan risiko usahatani seperti gagal panen, serangan hama penyakit dan terjadi fluktuasi harga.

Just dan Pope (1979 dalam Lawalata 2017), menyampaikan bahwa dalam keputusan alokasi penggunaan input risiko produksi memainkan peranan yang sangat penting, sehingga dapat mempengaruhi tingkat produktivitas yang dicapai.

Risiko berpengaruh terhadap pengambilan keputusan atau perilaku petani. Terdapat perbedaan antara petani yang menyukai risiko dan takut terhadap risiko. Petani yang takut terhadap risiko produksi menggunakan input secara berhatihati dan leboih sedikit. Sedangakan untuk petani yang menyukai risiko dan berani terhadap risiko input yang digunakan juga besar. (Pujiarto,2017).

Keengganan terhadap risiko dipengaruhi oleh karakteristik individu petani. Menurut Ellis (2003 dalam Lawaata 2017), menyatakan bahwa dinegara berkembang sebagian besar petani kecil menghindari risiko yang menyebabkan alokasi penggunaan input yang tidak efisien sehingga dapat mempengaruhi tingkat produktivitas usahatani.

Menurut Tajerin (2005 dalam Wardani 2015) dalam menghadapi risiko terdapat sikap atau perilaku petani yang cenderung berbeda. Petani dapat berprilaku menyukai risiko (risk lover), menghindari risiko (risk averter) atau netral terhadap risiko (risk neutral).

Penelitian ini penting dilakukan agar petani melakukan pertimbangan dalam pengelolaan dan perencanan usahatani padi organik dimasa datang serta bagi instansi sebagai masukan dalam rangka kebijakan peningkatan produksi padi organik dan mengurangi risiko usahatani padi organik. Terdapat dua tujuan dalam melakukan penelitian ini, untuk tujuan pertama yaitu menganalisis perilaku petani terhadap risiko, dan untuk tujuan kedua adalah mengetahui dan faktor-faktor yang mempengaruhi perilaku petani terhadap risiko usahatani padi organik di Desa Ketapang Kecamatan Susukan.

\section{METODE}

Waktu pelaksanaan penelitian dilakukan pada bulan Juni- Juli 2018 berlokasi di kecamatan Susukan, Kabupaten Semarang, Jawa Tengah. Di Kecamatan Susukan di Desa Ketapang terdapat paguyuban petani yang sudah lama berdiri dengan nama Paguyuban Petani Al Barokah yang mengembang usahatani padi organik yang sudah memenuhi Standar Nasional Indonesia sehingga masuk pasar ekspor dan telah mendapatkan pengakuan melalui sertifikasi Lembaga Sertifikasi Pertanian Organik (LSPO) Indonesian organic farming certification (INOFICE). Penelitian lokasi ini dilakukan secara sengaja (purposive).

Pada penelitian ini, pengambilan sampel dilakukan menggunakan simple random sampling, dengan jumlah populasi 334 menggunakan perhitunagn Solvin maka didapatlah 76 responden petani dalam penelitian ini.

Data primer dan data sekunder adalah jenis data yang digunakan dalam penelitian ini, untuk data primer didapat dari objek yang diteliti secara langsung, sedangkan data sekunder sebagai penguat data 
primer. (Sugiyono 2012). Dalam memperoleh data primer dengan melakukan observaasi, setelah itu melakukan wawancara dengan menggunakan menggunakan kuesioner kepada paetani padi organik. Untuk data sekunder di dapat diperoleh dari studi literatur pada buku, internet, jurnal, skripsi dan dari data instansi Dinas Pertanian dan Kehutanan Kecamatan Susukan.
Dalam pengambilan data penelitian ini dilakukan observasi terlebih dahulu dan mengamati kegiatan dan kondisi petani di Kecamatan susukan. Selanjutnya dilakukan penelitian dengan menggunakan kuesioner dengan menggunakan pertanyaan dan wawancara petani.

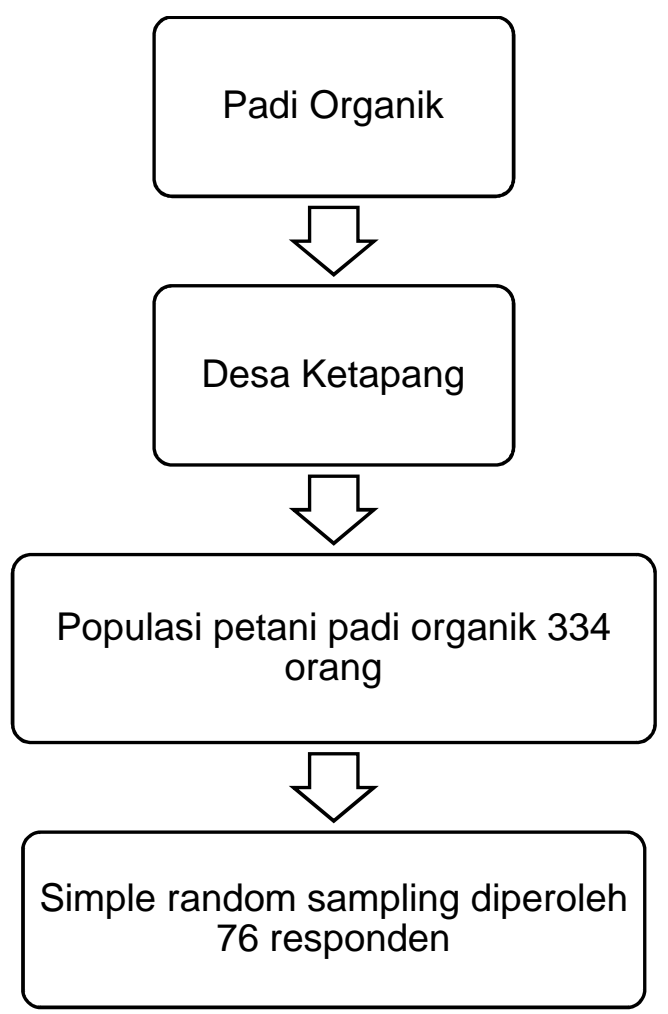

Diagram 1. Alur Pelaksanaan Metode Penelitian.

\section{ANALISIS DATA}

Analisis tujuan satu yaitu menganalisis perilaku petani terhadap risiko menggunakan fungsi produksi Cobb Douglas kemudian dianalisis dengan regresi linear berganda dengan model:

$$
\operatorname{Ln} Y=\operatorname{Ln} \beta 0+\operatorname{Ln} \beta 1 X 1+\operatorname{Ln} \beta 2 X 2+\operatorname{Ln} \beta 3 X 3+\operatorname{Ln} \beta 4 X 4+\operatorname{Ln} \beta 55+e
$$

Keterangan :

$\mathrm{Y} \quad=$ Hasil padi organik ( ton $/ \mathrm{Ha}$ )

$\mathrm{X} 1$ = Jumlah luas lahan yang ditanam $\mathrm{kg} / \mathrm{Ha}$ )

$\mathrm{X} 2=$ Benih $(\mathrm{Kg} / \mathrm{Ha})$

$\mathrm{X} 3=$ Pupuk organik $(\mathrm{Kg} / \mathrm{Ha})$

$\mathrm{X} 4$ = Pestisida organik $(\mathrm{Kg} / \mathrm{Ha})$;

$\mathrm{X} 5$ = Penggunan tenaga kerja $(\mathrm{HOK} / \mathrm{Ha})$ 
$\mathrm{E}=$ Faktor kesalahan yang diasumsikan terdistribusi normal dengan rata-rata nol dan varians konstan.

Setelah itu hasil variabel input yang digunakan adalah variabel yang paling berpengaruh kemudian memasukan penggunaan input tersebut menggunakan metode Moscardy dan de Janvry:

$$
K(s)=1 / \Theta(1-(P i . X i) /(P y . f i . \mu y))
$$

Keterangan :

$\theta=$ koefisien variasi dari produksi $(\theta=\delta / \mu)$ dimana $\delta=$ standar deviasi

dari produksi dan $\mu=$ produksi rata-rata.

$r \quad=$ harga produk

$f \quad=$ elastisitas produksi dari input

$X \quad=$ jumlah input $\mathrm{ke}-\mathrm{i}$

$P \quad=$ harga input ke

$\mu \quad=$ produksi rata-rata

$\mathrm{K}(\mathrm{S})$ = pengukuran parameter keengganan terhadap risiko Terdapat 3 kategori klasifikasi petani berdasarkan parameter penolakan risiko $\mathrm{K}(\mathrm{s})$ yaitu:

a. Menyukai risiko (risk lover) $(0<\mathrm{K}(\mathrm{s})$ $<0,4$ ) dengan kategori risiko rendah

b. Netral terhadap risiko (risk neutral) ( $0,4 \leq \mathrm{K}(\mathrm{s})<1,2)$ dengan kategori risiko menengah

c. Menghindari risiko atau menolak risiko (risk averter) $(1,2 \leq \mathrm{K}(\mathrm{s})<2,0)$ dengan kategori risiko tinggi

Analisis tujuan dua yaitu mengetahui faktor faktor yang mempengaruhi perilaku petani terhadap risiko menggunakan analisis regresi linear berganda. Model regresi linier berganda dalam penelitian ini:

$$
\operatorname{LnK}(\mathrm{S})=\operatorname{Ln} \alpha+\operatorname{Ln} \beta 1 \mathrm{~L}+\operatorname{Ln} \beta 2 \mathrm{U}+\operatorname{Ln} \beta 3 \mathrm{~N}+\operatorname{Ln} \beta 4 \mathrm{E}+\operatorname{Ln} \beta 5 \mathrm{P}+\operatorname{Ln} \beta 6 \mathrm{I}+\varepsilon
$$

Keterangan:

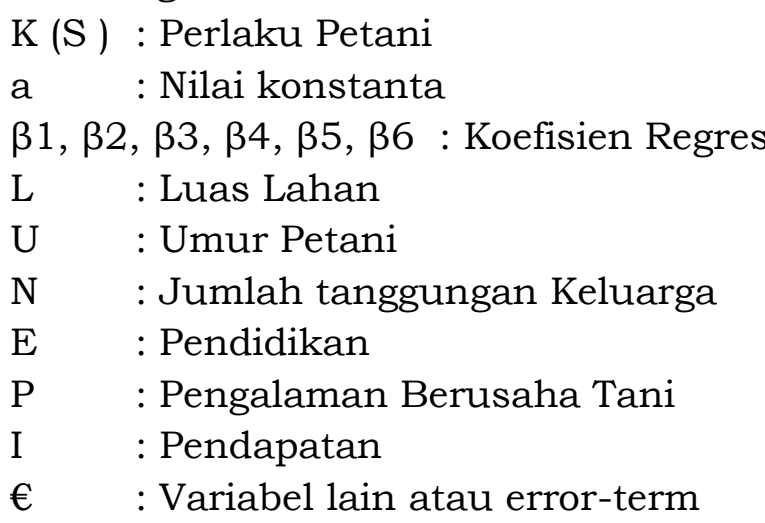

\section{Uji Simultan}

Tujuan dari uji simultan atau uji $F$ adalah untuk mengetahui pengaruh dari seluruh variabel dependen terhadap variabel dependen. dengan selang kepercayaan $90 \%$ yaitu dengan melakukan

perbandingan antar $\mathrm{F}$ hitung dengan $F$ tabel dengan pengujian hipotesis:

Kriteria pengujian yang dilakukan adalah bahwa jika Fhitung < Ftabel maka Ho diterima, tetapi jika Fhitung > Ftabel maka dilakukan penolakan terhadap Ho. Penolakan terhadap Ho artinya bahwa variabel bebas memiliki pengaruh terhadap 
variabel tidak bebas. Dan jika Ho diterima artinya bahwa tidak ada pengaruh antara variabel bebas terhadap variabel tidak bebas \secara serentak.

\section{Uji Partial}

Pengujian hipotesis secara parsial atau uji $\mathrm{T}$ digunakan untuk melihat pengaruh variabel independen secara individu terhadap variabel dependen dan untuk menguji koefisien regresi setiap variabel independen terhadap variabel dependen. (Sugiyono, 2012). Kriteria dalam pengujian ini adalah jika $t$ hitung lebih kecil dari $t$ tabel maka Ho diterima dan sebaliknya jika t hitung lebih besar $t$ tabel makan Ho ditolak yang berarti $\mathrm{H} 1$ diterima jika $\mathrm{t}$ hitung lebih besar dari t tabel yang artinya bahwa terdapat hubungan antara variabel independen terhadap variabel dependen. Sebaliknya jika $t$ hitung $<\mathrm{t}$ tabel, Ho diterima berarti variabel independen tak berhubungan dengan variabel dependen secara individu.

\section{Uji $\mathbf{R}^{2}$}

Uji $\mathrm{R}^{2}$ atau uji koefisien determinasi digunakan untuk mengetahui perubahan pada suatu variabel terhadap variabel yang lainnya. Nilai $\mathrm{R}^{2}$ memiliki kisaran angka dari 0 sampai 1 atau $\left(0<R^{2} \leq 1\right)$. Jika nilai dari $\mathrm{R}^{2}$ mendekati angka 1 maka hasil dari regresi tersebut baik, yang berarti bahwa variabel independen berpengaruh sangat besar terhadap variabel dependen. Apabila nilai dari $\mathrm{R}^{2}$ mendekati angka 0 maka hasil regresi masih kurang berpengaruh dari variabel independen terhadap variabel dependen. (Ghozali, 2006:50).

\section{HASIL DAN PEMBAHASAN}

Penggunaan input faktor produksi pada usahatani padi organik adalah benih, pupuk kandang, pupuk organik cair, pestisida organik dan tenaga kerja. Perilaku petani terhadap risiko usahatani padi organik digolong menjadi tiga yaitu menyukai risiko, netral terhadap risiko dan menolak atau menghindari risiko.

Tabel 2. Hasil Analisis Faktor- Faktor yang Mempengaruhi Perilaku Petani Terhadap risiko

\begin{tabular}{lcccccc}
\hline \multicolumn{1}{c}{ Variabel } & Koefisien & $\begin{array}{c}\text { Standar } \\
\text { eror }\end{array}$ & Nilai t & Sig & Tolerance & VIF \\
\hline Konstanta & 7,663 &, 705 & 10,867 &, 000 & & \\
Benih &, 247 &, 104 & 2,373 &, 020 &, 912 & 1,097 \\
P_kandang &, 049 &, 040 & 1,232 &, 222 &, 708 & 1,412 \\
p-organikcair &,- 034 &, 041 &,- 831 &, 409 &, 773 & 1,293 \\
Pestisida &,- 024 &, 040 &,- 592 &, 556 &, 789 & 1,267 \\
organik &,- 070 &, 031 & $-2,281$ &, 026 &, 723 & 1,384 \\
TK & & & & &
\end{tabular}

Keterangan: $\mathrm{R}^{2}=0,463$

durbin watson $=1,633$

F hitung $\quad=3,825 \quad$ Ftabel $=2,35$

Standar error $=0,17$

Sumber : Analisis Data primer, 2018 
Berdasarkan perhitungan nilai $\mathrm{F}$ hitung 3,825 > 2,35 $\mathrm{F}$ tabel, yang berati variabel benih, pupuk kandang, pupuk organik, pestisida organik dan tenaga kerja memiliki pengaruh yang nyata terhadap variabel produksi padi organik secara serentak.

Nilai $R^{2} \quad 0,463$ menunjukan bahwa variabel independen berpengaruh terhadap variabel dependen yang berarti $46,5 \%$ tingi rendahnya produksi dapat dijelaskan oleh variabel independen seperti benih padi organik, pupuk kandang, pupuk organik cair, pestisida cair serta penggunaan tenaga kerja.

Uji multikolinearitas pada penelitian ini dapat dilihat dari nilai VIF (Variance Inflation Factor) yaitu kurang dari 10 dan nilai Tolerance lebih dari 0,1 agar bebas dari multikolinearitas. Pada tabel 4.5 hasil uji multikolinearitas nilai VIF pada variabel, benih, pupuk kandang, pupuk organik cair, pestisida organik, dan tenaga kerja kurang dari 10 yang dapat disimpulkan bahwa tidak terjadi multikolinearitas.

Berdasarkan tabel hasil analisis regersi faktor yang mempengaruhi produksi pada tabel 1. Bahwa variabel yang memiliki pengaruh terhadap produksi adalah benih padi organik dan penggunaan tenaga kerja. Dilihat dari koefisien regresi variabel jumlah benih yang paling berpengaruh terhadap produksi artinya $1 \mathrm{Kg}$ benih dapat meningkatkan produksi sebesar 0,247 Kg, sehingga variabel input ini yang dijadikan dasar perhitungan parameter keenagganan $\mathrm{K}(\mathrm{S})$ atau perilaku petani terhadap risiko.

\section{Perilaku Petani Terhadap Risiko}

Hasil analisis data pada tabel 1 dari 5 faktor produksi yang paling signifikan adalah jumlah benih, oleh sebab itu variabel jumlah benih yang digunakan sebagai parameter penentuan kategori perilaku petani terhadap risiko usahatani padi organik.

Tabel 3. Nilai Faktor Yang Digunakan Untuk Menentukan Kriteria K(s)

\begin{tabular}{|c|c|c|c|c|c|c|}
\hline Uraian & $\Theta$ & $\mathrm{P} x$ & $\mathrm{X} i$ & PY & Fi & $\mu y$ \\
\hline Benih & 0,723 & $\begin{array}{l}\text { Harga benih } \\
\text { setiap petani } \\
\text { padi organik }\end{array}$ & $\begin{array}{l}\text { Jumlah } \\
\text { benih } \\
\text { setiap } \\
\text { petani padi } \\
\text { organik }\end{array}$ & $\begin{array}{l}\text { Harga } \\
\text { produk } \\
\text { setiap } \\
\text { petani padi } \\
\text { organik }\end{array}$ & 0,247 & 1.279 \\
\hline
\end{tabular}

Sumber : Analisis Data Primer, 2018

Produksi rata-rata padi organik adalah $1,279 \mathrm{~kg}$, dan koefisien variasi dari produksi adalah 0,723 , elastisitas produksi dari benih yaitu 0,723 . Rata - rata harga benih $6.576 / \mathrm{kg}$ dan jumlah benih yang digunakan dalam usahatani padi organik $10 \mathrm{Kg} / \mathrm{m}^{2}$. Produk yang dihasilkan berupa beras dengan rata rata harga $12.460 / \mathrm{Kg}$. Penentuan parameter K (s) berdasarkan metode Moscardi and de Janvry (1997) adalah:

1. Risk lover $(0<\mathrm{Ks}<0,4)$

2. Risk neutral $(0,4 \leq \mathrm{Ks} \leq 1,2)$

3. Risk averter $(1,2<\mathrm{K}(\mathrm{s})<2,0$ 
Tabel 4. Hasil Analisis Perilaku Petani Terhadap Risiko Usahatani Padi Organik

\begin{tabular}{ccc}
\hline $\begin{array}{c}\text { Kriteria perilaku petani } \\
\text { terhadap risiko }\end{array}$ & Jumlahpetani & Persentase \\
\hline Risk lover & 0 & $0 \%$ \\
Risk neutral & 0 & $0 \%$ \\
Risk averter & 76 & $100 \%$ \\
\hline Jumlah & 76 & $100 \%$ \\
\hline
\end{tabular}

Sumber : Analisis Data Primer, 2018

Berdasarkan tabel analisis perilaku petani terhadap risiko usahatani padi organik terhadap risiko terdapat 76 petani padi organik dengan prentase $100 \%$ memiliki perilaku menghindari risiko ( risk averter), yang memiliki perilaku menyukai risiko (risk lover) dan netral terhadap risiko (risk neutral) berjumlah 0 dengan presentasi $0 \%$ atau tidak ada yang memiki perilaku tersebut. Berdasarkan nilai $\mathrm{K}(\mathrm{S})$ dengan rata-rata 1,4 yang berarti $\mathrm{K}(\mathrm{s})$ lebih besar dari sama dengan 1,2 dan kurang dari sama dengan 2,0 yang dapat disimpulkan sesuai dengan kriteria perilaku menurut Moscardi de and Janvry (1997) bahwa petani lebih menghindari risiko dalam usahatani padi organik didesa Ketapang.

\section{Faktor faktor Yang Mempengaruhi Perilaku Petani Terhadap Risiko}

Faktor- faktor yang di duga mempengaruhi perilaku petani terhadap risiko adalah luas lahan, aumur, pendidikan, pengalaman, jumlah anggota keluarga, dan pendapatan. Hasil analisis perilaku petani terhadap risiko dapat dilihat tabel dibawah ini.

Tabel 5. Faktor-Faktor yang Mempengaruhi Perilaku Petani Terhadap Risiko

\begin{tabular}{lcccccc}
\hline \multicolumn{1}{c}{ Variabel } & Koefisien & $\begin{array}{c}\text { Standar } \\
\text { error }\end{array}$ & Nilai t & sig & Tolerance & VIF \\
\hline Konstanta & 0,362 & 0,035 & 10,438 & 0,000 & & \\
Luas lahan & 0,015 & 0,001 & 15,583 & 0,000 & 0,771 & 1,296 \\
Umur & $-0,001$ & 0,004 & $-0,394$ & 0,695 & 0,449 & 2,225 \\
Pendidikan & 0,000 & 0,001 & $-0,084$ & 0,933 & 0,889 & 1,125 \\
Pengalaman & 0,001 & 0,001 & 1,167 & 0,248 & 0,483 & 2,070 \\
Jml_angt_klrg & $-0,001$ & 0,002 & $--0,858$ & 0,394 & 0,850 & 1,176 \\
Pendapatan & $-0,004$ & 0,002 & $-2,268$ & 0,027 & 0,765 & 1,301 \\
petani & & & & & & \\
\hline
\end{tabular}

Keterangan:

$\mathrm{R}^{2}=0,858$

Fhitung $=61,379 \quad$ Ftabel $=2,2$

Durbin watson $=1,797$

Sumber : Analisis Data Primer, 2018

Perhitungan nilai $\mathrm{F}$ hitung $61,379>2,23 \mathrm{~F}$ tabel dengan nilai signifikansi 0,000 pada tabel 5 yang berarti simultan luas lahan, umur, pendidikan, pengalaman, jumlah tanggungan keluarga dan pendapatan signifikan terhadap kriteria perilaku $\mathrm{K}(\mathrm{s})$. Nilai $\mathrm{R}^{2}$ dapat dilihat pada tabel 5 
adalah 0,858 menunjukan adanya pengaruh variabel independen terhadap variabel dependen dengan nilai sebesar 0,858 atau $85,8 \%$. Semakin mendekati $100 \%$ maka penelitian ini semakin baik. Pembahasan mengenai faktor faktor yang mempengaruhi perilaku petani terhadap risiko adalah:

1. Luas lahan

Rata-rata luas lahan petani padi organik di Desa Ketapang adalah 0,273 Ha dan jika dikonversikan menjadi 5,14 ha, luas lahan maksimal yang dimiliki adalah 0,85 ha dan luas lahan minimal yang dimiliki petani adalah 0,08 Ha. Variabel luas lahan memiliki pengaruh yang positif terhadap perilaku petani terhadap risiko dengan nilai $t$ hitung adalah $15,583>1.994$ ttabel dan nilai signifikan 0,000 yang berarti luas lahan berpengaruh positif terhadap perilaku petani usahatani padi organik atau parameter keengganan $(\mathrm{ks})$ terhadap risiko. Dalam hal ini sejalan dengan pendapat Pujiharto ( 2107:70) yang berarti bahwa semakin besar luas lahan maka semakin berani petani terhadap risiko.

2. Umur

Umur petani padi organik di Desa ketapang rata-rata adalah 53 tahun. Berdasarkan hasil uji t di dapat $t$ hitung - 0,394 $<1,994 \mathrm{t}$ tabel dan nilai signifikansi 0,695 > 0,05 yang berarti variabel umur tidak berpengaruh nyata terhadap perilaku petani terhadap risiko. Dalam hal ini sesuai dengan penelitian Pujiharto dan Wahyuni (2017) menyatakan bahwa perbedaan umur pada petani serta banyaknya pengalaman dan keterampilan tidak berpengaruh pada perilaku petani terhadap risiko.

3. Pendidikan

Rata-rata tingkat pendidikan formal petani adalah Sekolah Dasar (SD), dengan pendidikan terendah SD dan penidikan tertinggi SMA. Pada tabel 4 nilai uji $\mathrm{t}$ hitung $-0,084<1,994 \mathrm{t}$ tabel dengan signifikansi 0,933 yang dapat disimpulkan Ho diterima $\mathrm{H} 1$ ditolak yang berarti pendidikan tidak berpengaruh nyata terhadap kriteria perilaku $\mathrm{K}(\mathrm{s})$. Hal ini berarti bahwa tinggi rendahnya pendidikan tidak menurunkan keengganan terhadap risiko atau netral pada risiko.

4. Pengalaman

Rata- rata pengalaman usahatani di Desa Ketapang adalah 21 tahun dengan pengalaman terendah 4 tahun dan pengalaman tertinggi 40 tahun. Pada tabel 4.7.1 nilai uji $\mathrm{t}$ thitung $1,167<1,994$ ttabel dengan signifikansi 0,248 yang dapat disimpulkan bahwa pengalaman tidak berpengaruh nyata terhadap kriteria perilaku $\mathrm{K}(\mathrm{s})$ yang berarti bahwa lamanya pengalaman petani dalam usahatani padi organik tidak mempengaruhi perilaku petani terhadap risiko. Berdasarkan penelitian dari Lawalata dkk,. ( 2017) menyampaikan bahwa semakin lama usahatani maka membuat petani semakin berani terhadap risiko.

5. Jumlah anggota keluarga

Berdasarkan analisis pada tabel uji $\mathrm{t}$ nilai thitung $-0,858<1,994$ ttabel dengan signifikansi 0,394 yang dapat disimpulkan Ho diterima dan $\mathrm{H} 1$ ditolak yang berarti jumlah tanggungan keluarga tidak berpengaruh 
terhadap kriteria perilaku $\mathrm{K}(\mathrm{s})$ keengganan risiko atau perilaku petani terhadap risiko. Petani padi organik didesa ketapang memiliki usaha sampingan ada yang membuka usaha dan beternak, sesuai dengan penelitian Lawalata dan Wahyuni (2017) yang mengemukakan bahwa tidak terdapat pengaruh yang nyata antara jumlah tanggungan keluarga terhadap perilaku petani. Petani dapat memenuhi kebutuhan keluarga dari luar usahatani.

6. Pendapatan petani

Berdasarkan hasil analisis regresi paa tabel 4.7.1 nilai t hitung -2,268 $<1,994$ t tabel dengan signifikansi 0,0247 yang dapat disimpulkan bahwa pendapatan berpengaruh negatif terhadap kriteria perilaku $\mathrm{K}(\mathrm{s})$, yang berarti dengan besarnya pendapatan akan membuat petani padi organik mengurangi keengaganan terhadap risiko atau dapat disimpulkan lebih berani terhadap risiko. Rata-rata pendapatan petani padi organik dalam konversi $1 \mathrm{Ha}$ adalah $\mathrm{Rp}$ 40.0776.000/Ha, dan pendapatan tertinggi sebesar Rp 78.233.294/ ha dan pendapatan terendah $\mathrm{Rp}$ 6.842.143/ha. Dilihat dari pendapatan kotor petani dapat dikatakan bahwa pendaptan petani tinggi akan tetapi dengan pendapatan yang tinggi, risiko yang dihadapi juga tinggi. Menurut Pujiharto dan Wahyuni menyatakan bahwa besar kecilnya pendapatan berpengaruh terhadap perilaku petani terhadap risiko.

\section{KESIMPULAN DAN SARAN}

\section{Kesimpulan}

Faktor yang mempengaruhi tingakat produksi adalah benih dan tenaga kerja dilihat dari signifikansinya bahwa variabel benih padi organik dan penggunaan tenaga kerja berpengaruh nyata terhadap variabel produksi padi organik. Variabel yang digunakan untuk mengukur perilaku petani terhadap risiko adalah benih, dikarenakan benih sangat berkontribusi dan berpengaruh terhadap produksi. Hasil analisis perilaku petani terhadap risiko usahatani padi organik yaitu semua petani atau semua jumlah petani responden penelitian menolak risiko (risk averter) dengan jumlah 76 petani yang berarti $100 \%$ petani menolak risiko. Faktor-faktor yang mempengaruhi perilaku petani adalah luas lahan dan pendapatan petani.

\section{Saran}

1. Untuk memperoleh hasil yang tinggi sesuai harapan petani, alangkah baiknya petani berani mengambil risiko atau menghadapi risiko sesuai dengan penerapan bahwa dengan risiko yang tinggi keuntungan yang didapat juga tinggi.

2. Bagi pemerintah sebaiknya dapat memberikan kebijakan -kebijakan yang mendukung pertanian organik agar semakin banyak petani yang menerapkan pertanian organik.

\section{DAFTAR PUSTAKA}

Andoko, Agus. (2002). Budidaya Padi Secara Organik. Jakarta: Penebar

Ghozali, Imam. 2006. Analisis Multivariat Konsep dan Aplikasi dengan SPSS. Semarang: Universitas Diponegoro. 
Kadarsan, H.1992. Keuangan Pertanian dan Pembiayaan Perusahaan Agribisnis.

PT Gramedia. Jakarta.

Lawalata M, Dwidjono H.D, Hartono Slamet. 2017. Risiko Usaha Tani Bawang Merah di Kabupaten Bantul. Jurnal Agribisnis Sumatra Utara vol.10 No

Moscardi, E. and Alain de Janvry. 1977. Attitudes toward Risk among Peasants: An Econometric Approach: American Journal of Agricultural Economics, 59 (4) :710-716

Ningsih, K. 2013. Risiko Produksi dan Inefisiensi Teknis Usaha Tani Padi Gogopada Agro Ekosistem
Lahan Kering. Jurnal Agronomics, 2 (1): 1-15

Pujiharo dan Wahyuni. 2017. Analisis Perilaku Petani Terhadap: Penerapan Moscardi and de Janvry Model. Jurnal AGRITECH : Vol. XIX No. 1 Juni $2017: 65-73$

Sugiyono. 2012. Metode Penelitian Kuantitatif, Kualitatif dan R\&D. Bandung: CV. Alfabeta

Tajerin, T. \& Noor, M. 2005. Analisis EfisiensiTeknik Usaha Budidaya Pembesaran Ikan

Wardhani, S. 2015. Perilaku Petani Terhadap Risiko Usaha Tani di Kabupaten Klaten. Agrobisnis Departemen, Program Pascasarjana Universitas Sebelas Maret. 